\title{
Opening Metal-Organic Frameworks Vol. 2: Inserting Longer Pillars into Pillared-Paddlewheel Structures through Solvent-Assisted Linker Exchange
}

Olga Karagiaridi, ${ }^{\dagger, \perp}$ Wojciech Bury, ${ }^{\dagger, \ddagger} \perp$ Emmanuel Tylianakis, ${ }^{\S, \|}$ Amy A. Sarjeant, ${ }^{\dagger}$ Joseph T. Hupp, ${ }^{*}, \dagger$ and Omar K. Farha*, ${ }^{\dagger}$

\begin{abstract}
${ }^{\dagger}$ Department of Chemistry and International Institute for Nanotechnology, Northwestern University, 2145 Sheridan Road, Evanston, Illinois 60208, United States

${ }^{\ddagger}$ Department of Chemistry, Warsaw University of Technology, Noakowskiego 3, 00-664 Warsaw, Poland

${ }^{\S}$ Department of Chemical and Biological Engineering, Northwestern University, 2145 Sheridan Road, Evanston, Illinois 60208, United States

"Materials Science and Technology Department, University of Crete, P.O. Box 2208, 71409 Heraklion, Crete, Greece
\end{abstract}

Supporting Information

ABSTRACT: Solvent-assisted linker exchange (SALE) was performed on a pillared-paddlewheel metal-organic framework (MOF), SALEM-5, to achieve incorporation of longer linkers into the material. The 9- $\AA$ meso-1,2-di(4-pyridyl)-1,2ethanediol pillar of SALEM-5 was successfully replaced by 11$\AA$, 14- $\AA$, and 17- $\AA$ pillars to generate daughter MOFs SALEM6, SALEM-7, and SALEM-8. The daughter frameworks possess more open cages, as was demonstrated by structural modeling from the powder X-ray diffraction patterns, and larger solvent accessible space, as was demonstrated by thermogravimetric analysis. Finally, a study was performed to examine the effect of $\mathrm{p} K_{\mathrm{a}}$ of monoprotonated dipyridyl pillars (as an indicator of the $\mathrm{Zn}-\mathbf{L}$ bond strength) on the outcome of SALE.

KEYWORDS: metal-organic frameworks, solvent-assisted linker exchange, $p K_{a}$

\section{INTRODUCTION}

Metal-organic frameworks (MOFs) constitute a highly investigated class of hybrid materials that have attracted an unprecedented amount of research effort over the past decade. Their highly porous ${ }^{1,2}$ and modular nature endows them with a vista of attractive properties, and their potential has been examined in many different areas such as gas storage, 3,4 catalysis, ${ }^{5}$ sensing, ${ }^{6}$ separations, ${ }^{7}$ removal of hazardous materials, ${ }^{8}$ and light harvesting. ${ }^{9-13}$

One of the greatest challenges in MOF research lies in devising a sufficiently diverse set of synthetic pathways to enable desired new MOF structures to be routinely obtained experimentally. Several factors can make this surprisingly difficult, even when the desired new MOFs constitute analogues of known materials. First, the traditional solvothermal synthesis of MOFs may preclude the incorporation of certain linkers de novo (e.g., free-base porphyrins). ${ }^{14}$ Second, precursors for nodes and other metal sites (typically, labile metal complexes) are free to react with multitopic linkers, thereby making the incorporation of coordinatively unsaturated metals difficult. Finally, there is limited control over the topological arrangement of the metal nodes and the linkers; de novo assembly may favor the production of low-energy structures, which are not always the desired products. ${ }^{15}$ Numerous procedures have been devised to circumvent these obstacles, including templating, ${ }^{16}$ use of porogens, ${ }^{17}$ prefabrication of structural building blocks, ${ }^{18}$ stepwise synthesis, ${ }^{14}$ and postsynthesis modification of either the ligand or the metal node. $^{19}$

A recently discovered and very promising method that can be applied toward the solution of the aforementioned problems is solvent-assisted linker exchange (SALE)..$^{20-23,45}$ Appealingly facile in its implementation, SALE involves exposing parent MOF crystals to a concentrated solution of linkers of choice in a carefully selected solvent. A successful outcome is a daughter MOF structure that possesses the topology of the parent combined with the linkers from the reaction solution. Even though Robson predicted SALE as early as in $1990,{ }^{24}$ the actual conceptualization of the process was slow to develop. Kitagawa and co-workers followed by Chen and co-workers performed a series of experiments in 2004 that involved linking 2D paddlewheel layers with bipyridyl pillars to obtain $3 \mathrm{D}$

Received: May 29, 2013

Revised: August 2, 2013

Published: August 22, 2013 
structures. ${ }^{25,26}$ Zhou's group was perhaps the first to perform SALE in molecular metal-organic polyhedra, in which they replaced the existing pillars with monodentate and bidentate ligands. ${ }^{27,28}$ However, the first SALE in MOFs was implemented in 2011 by Choe and co-workers. They replaced $N, N^{\prime}$-di-4- pyridylnaphthalenetetracarboxydiimide linkers in a pillared-paddlewheel porphyrin MOF with 4,4'-bipyridyl moieties. ${ }^{29}$

Shortly afterward, Cohen and co-workers achieved solid-tosolid and solution-to-solid replacement of benzene-dicarboxylate derivatives in the notoriously robust UiO-66 structure. ${ }^{30}$ Since then, there has been a rapid increase of interest in the exploitation of SALE, and this method has been applied toward resolving a variety of challenges in MOF synthesis, such as modification of chemically "inert" structures, ${ }^{20,31}$ bulk preparation of comparatively high-energy polymorphs, ${ }^{21}$ opening of apertures, ${ }^{21}$ synthesis of catalytically active materials, ${ }^{22}$ and control over catenation. ${ }^{23}$

Pillared-paddlewheel MOFs have been utilized as model systems in many reports regarding SALE. ${ }^{22,23,29,32}$ This is not surprising, as the composition of these materials suggests facile replacement of the relatively weakly bound pillars. Nevertheless, a perceived limitation of SALE for pillared-paddlewheel MOFs is the challenge associated with replacing existing pillars with ones of greater length, with retention of the parent topology.

In the present work, we have successfully used SALE to incorporate a variety of longer linkers into a pillaredpaddlewheel structure. The parent material Solvent-Assisted Linker Exchanged Material-5 (SALEM-5, Scheme 1) features meso-1,2-di(4-pyridyl)-1,2-ethanediol (L1) pillars that are approximately $9 \AA$ long. The monoprotonated conjugate-acid of $\mathbf{L} 1$ is moderately acidic $\left(\mathrm{p} K_{\mathrm{a}}=4.68\right)$. We hypothesized that the relatively low $\mathrm{p} K_{\mathrm{a}}$ of the acid would render the corresponding pillar fairly susceptible to linker exchange. ${ }^{33}$ The pillars connect layers of 1,4-dibromo-2,3,5,6-tetrakis(4carboxyphenyl)benzene (L2), a tetra-carboxylate specifically designed by our group to inhibit catenation by preventing access of building blocks through the $x y$-plane of the crystal structure. ${ }^{34}$ The utilization of $\mathbf{L} 2$ thus ensures the lack of catenation in the parent and daughter SALE materials. Here, we examine two concepts: (i) the incorporation of longer (11 $\AA$, $14 \AA$, and $17 \AA$ ) pillars into SALEM-5 and (ii) the effect of the $\mathrm{p} K_{\mathrm{a}}$ of the conjugate acid of the pillar as a predictor of the outcome of SALE.

\section{RESULTS AND DISCUSSION}

SALEM-5, as its name reveals, is in itself a material produced through SALE. Even though the bromine-free analogue of SALEM-5 (DOMOF) is known, ${ }^{35}$ attempts to access the brominated analogue via direct (de novo) synthesis invariably yielded 2D sheets of zinc clusters linked by L2. As a result, we resorted to performing SALE of $\mathbf{L} 1$ into a pillared-paddlewheel material previously synthesized by us that features LO pillars and L2-based sheets (Scheme 1). ${ }^{34}$ This SALE reaction proved facile, yielding SALEM-5 overnight.

In our attempts to incorporate longer linkers into the SALEM-5 framework, we initially selected a daughter linker that was only slightly longer than the 9-Å parent. Our choice was the 11- $\AA$ pillar L3. The presence of four nonstructural methyl groups endows L3 with good solubility in solvents used for SALE (e.g., N,N-dimethylformamide) and facilitates the monitoring of its insertion by ${ }^{1} \mathrm{H}$ NMR. To our pleasant surprise, after $24 \mathrm{~h}$ of SALE at $100{ }^{\circ} \mathrm{C}$ using 4 equiv. of $\mathrm{L} 3,{ }^{1} \mathrm{H}$
Scheme 1. (top) Summary of the SALE Reactions Performed on the SALEM-5 System; (bottom) Representation of Structures of Linkers Used in the Experiments
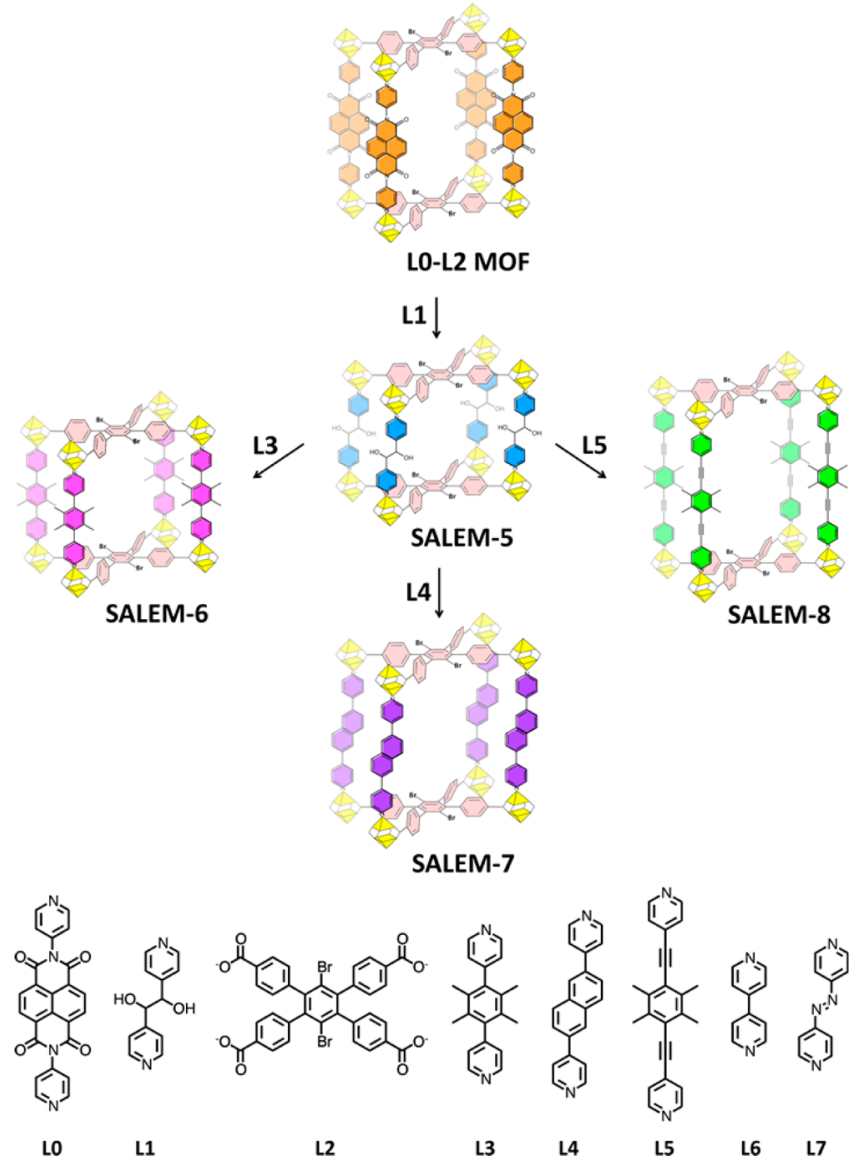

NMR showed $100 \%$ replacement of the parent $\mathbf{L} 1$ pillars by the daughter linker (Figure S3, Supporting Information). The crystallinity of the new structure, SALEM-6, was examined by powder X-ray diffraction (PXRD) in the presence of solvent in a spinning capillary, in order to avoid preferential orientation and preserve the integrity of the material. ${ }^{14,36}$ The position of the first peak at $2 \theta=4.76^{\circ}$ suggests that SALEM-6 possesses a larger unit cell than SALEM-5, which yields a first reflection peak at $2 \theta=5.60^{\circ}$ (Figure 1, vide infra).

Inspired by the success of SALEM-6, we wondered whether we could insert an even longer pillar into SALEM-5. The 14- $\AA$ long pillar L4 was selected. Daily monitoring of the SALE reaction by ${ }^{1} \mathrm{H}$ NMR indicated a steady increase in the content of L4; the progress of the reaction was expedited by replacing the solution with fresh batches when the rate of linker replacement plateaued. By day four, the replacement of $\mathbf{L} \mathbf{1}$ by L4 exceeded 90\% (Figures S4 and S6, Supporting Information). Paralleling data obtained for SALEM-6, the PXRD pattern for the L4-SALE product SALEM-7 indicated an even smaller angle for the first reflection peak $\left(2 \theta=4.20^{\circ}\right)$ and therefore an even larger unit cell.

Finally, to investigate the limits of SALE, we experimented with the replacement of $\mathbf{L 1}$ by the pillar L5, which possesses a structure analogous to that of $\mathbf{L 3}$, but at $17 \AA$, it is almost twice as long as the parent pillar. The SALE reaction proceeded at a very slow rate, presumably due to the great strain associated with the incorporation of such a large pillar. ${ }^{39}$ Indeed, two weeks were required for the reaction to approach completion 


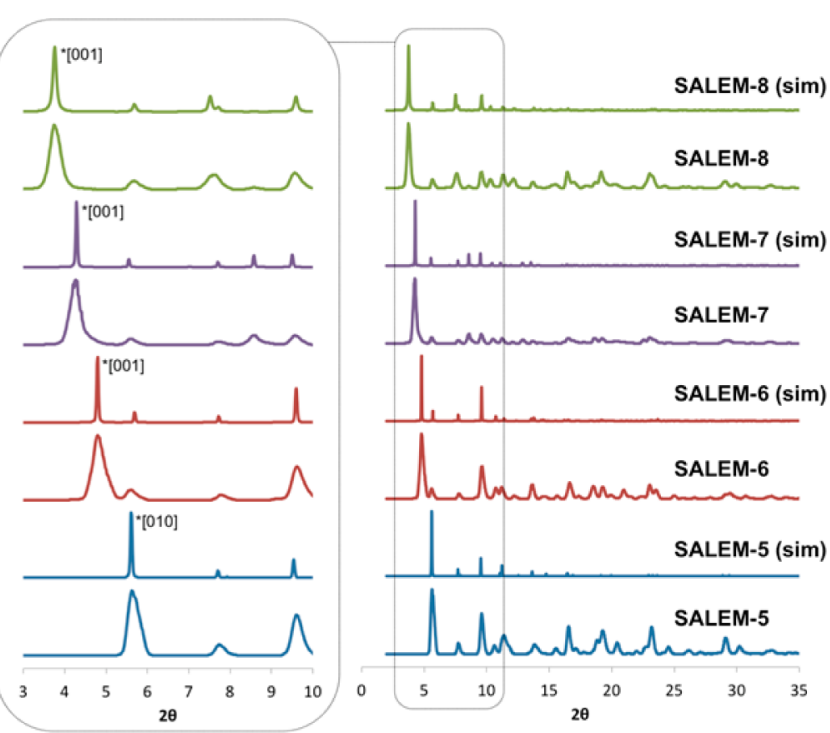

Figure 1. Experimental and simulated PXRD patterns of SALEM-5, SALEM-6, SALEM-7, and SALEM-8.

(>90\% replacement; see Figures S5 and S7, Supporting Information). As was the case with L4, replacement of the solution with fresh batches facilitated the progress of the reaction. Not surprisingly, PXRD revealed that the first reflection peak lies at an even lower angle $\left(2 \theta=3.72^{\circ}\right)$.

One may wonder about the nature of the SALE process when it involves incorporation of larger pillars. At a first glance, it seems that dissolution-reassembly is the only plausible way for such reactions to occur. However, a photographically monitored SALE experiment performed on a single crystal of SALEM-5 exposed to L3 under standard reaction conditions revealed that the crystal does not appreciably change in morphology through the course of the reaction, even when the reaction is allowed to proceed beyond the time necessary to achieve $>90 \%$ exchange to L3 on a bulk sample of SALEM-5 (Figure 2). This suggests that if dissolution-reassembly does

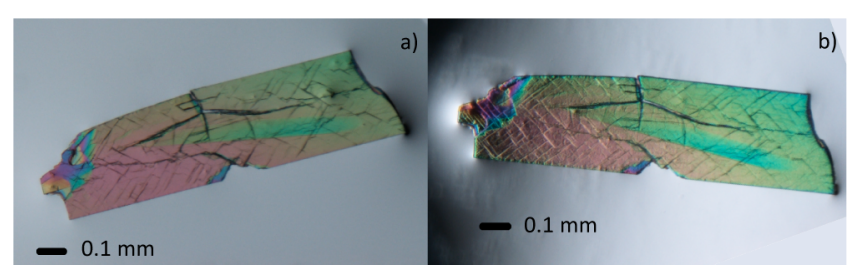

Figure 2. (a) Crystal of SALEM-5 and (b) the same crystal transformed to SALEM-6 after undergoing SALE to L3.

occur, its rate is too slow to be observed by the single-crystal experiment, which involves photographing the crystal every few hours or days. Whatever the process of incorporation of longer pillars into SALEM-5 may be (single crystal-to-single crystal or dissolution-reassembly), it apparently occurs very gradually, and the parent crystals do not observably change their morphology.

Unfortunately, the crystal quality of the SALEM-5 daughter materials was too poor for a single-crystal structural determination to be performed. ${ }^{40}$ As a result, to confirm the structures of these products, we resorted to modeling the structures of these materials from the PXRD patterns using a procedure described previously (Supporting Information). ${ }^{23}$ The structures of SALEM-5, SALEM-6, SALEM-7, and
SALEM-8 were constructed in silico and optimized using the lattice parameters obtained from the experimental PXRD patterns (Table 1). The experimental PXRD patterns of the

Table 1. Length and $\mathrm{pK}_{\mathrm{a}}$ Values of the Relevant Linkers Used in the Pillared-Paddlewheel Structures, and Lattice Parameters of the Simulated Structures of SALEM-5, SALEM-6, SALEM-7, and SALEM-8

\begin{tabular}{|c|c|c|c|c|}
\hline pillar & length $[\AA]^{37}$ & $\mathrm{p} K_{\mathrm{a}}^{38}$ & MOF structure & unit cell dimensions $[\AA]$ \\
\hline \multirow[t]{3}{*}{ L1 } & 8.795 & 4.68 & SALEM-5 & $a=11.4700$ \\
\hline & & & & $b=15.7553$ \\
\hline & & & & $c=15.7553$ \\
\hline \multirow[t]{3}{*}{ L3 } & 11.440 & 4.86 & SALEM-6 & $a=11.4439$ \\
\hline & & & & $b=15.5304$ \\
\hline & & & & $c=18.5173$ \\
\hline \multirow[t]{3}{*}{ L4 } & 13.527 & 4.75 & SALEM-7 & $a=11.4707$ \\
\hline & & & & $b=15.9200$ \\
\hline & & & & $c=20.6200$ \\
\hline \multirow[t]{3}{*}{ L5 } & 16.511 & 4.21 & SALEM-8 & $a=11.4439$ \\
\hline & & & & $b=15.5304$ \\
\hline & & & & $c=23.5000$ \\
\hline L6 & 7.079 & 4.44 & & \\
\hline L7 & 9.080 & 3.62 & & \\
\hline
\end{tabular}

SALE materials and their respective simulated patterns are compared in Figure 1, and it can be seen that they are in excellent agreement. Based on the simulated PXRD patterns, we were able to index the unit cells. Since the 2D sheets formed by $\mathbf{L} 2$ lie along the unit cell axes $a$ and $b$, it is the change in the unit cell dimension along the $c$-axis that is indicative of the successful replacement of the $\mathbf{L} 1$ pillar with one of a different length. The observed [001] peak in SALEM-6, SALEM-7, and SALEM-8 corresponds to the reflection coming from along the direction of the dipyridyl pillars; therefore, the observed increasingly lower-angle positions of this peak in the materials clearly indicate an elongation of the unit cells in the direction of the $c$-axis. Thermogravimetric analysis (TGA) experiments further support these data, as they show more than $50 \%$ solvent-accessible space in these structures and greater solventaccessible space in materials with longer linkers and larger cages. (Figures S9-S11, Supporting Information).

Data obtained through $\mathrm{N}_{2}$ sorption measurements may serve as additional support for the incorporation of longer linkers into SALEM-5 through SALE. So, despite the notorious difficulty associated with the activation of this family of pillaredpaddlewheel MOFs, such measurements were performed on SALEM-5 and SALEM-7. ${ }^{41-43}$ Density functional theory (DFT) pore size distribution reveals the presence of a pore with the width of $8.6 \AA$ in SALEM-5; SALEM-7, on the other hand, features an $11.8 \AA$ pore. The increase in pore width following the SALE of L1 in SALEM-5 by L4 is consistent with the fact that the pillars L1 and L4 differ in length by $4.5 \AA$ (Figure S20, Supporting Information).

It is evident from the results that incorporation of longer pillars into pillared-paddlewheel structures through SALE is feasible. Moreover, we observed that the utilization of a longer incoming linker does not necessarily lead to increased times for the SALE reaction to be completed. For example, we previously observed that the exchange of the DOMOF L1 pillar for 4,4'bipyridine (L6, approximately $7 \AA$ Å long; see Table 1) took place overnight - just as rapidly as the replacement of the same parent linker by L3, even though the latter is $2 \AA$ longer than 
the parent linker. At the same time, the SALE reaction leading to the replacement of the $\mathbf{L} \mathbf{1}$ linker by $4,4^{\prime}$-azobis(pyridine) (L7), a linker of roughly the same length as L1, needed about three days to come to completion. ${ }^{23}$ These observations made us ask whether, along with the linker length, the $\mathrm{p} K_{\mathrm{a}}$ of the conjugate acid of the incoming linker is a predictor of the rate of SALE. Linkers with higher conjugate acid $\mathrm{p} K_{\mathrm{a}}$ values form stronger bonds with the zinc centers and lead to more energetically favored structures.

We wanted to examine whether the $\mathrm{Zn}-\mathbf{L}$ bond strength plays a role in engendering preferential incorporation of a pillar when the parent MOF crystals are exposed to an equimolar mixture of candidate replacement pillars. Thus, we performed a series of mixed linker experiments, in which we exposed SALEM-5 crystals to pairs of different pillars (Scheme 2). We

Scheme 2. Summary of the Mixed Linker Reactions Performed on SALEM-5

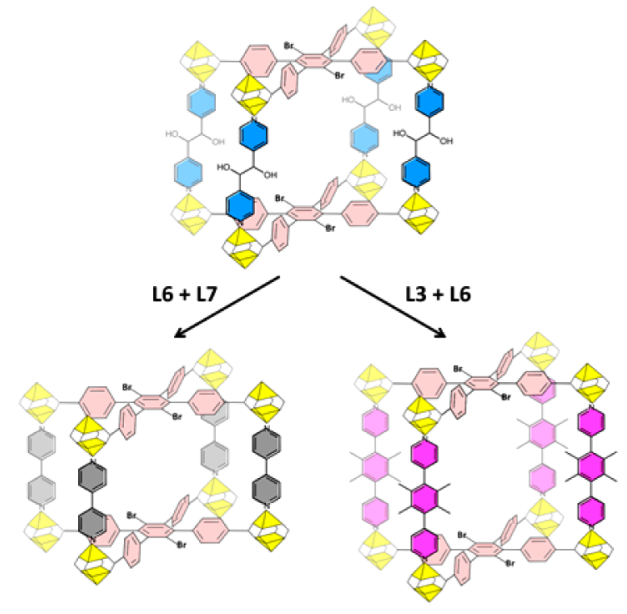

deliberately selected a pair of pillars with a small difference in conjugate acid $\mathrm{p} K_{\mathrm{a}}$ and a pair in which there was a marked difference. At the same time, the selected pillars differed in length, so that we could study whether it is the linker length or the strength of the $\mathrm{Zn}-\mathrm{L}$ bond that determines the linker distribution over the course of the SALE reaction.

In the first experiment, we exposed SALEM-5 crystals to an equimolar mixture of L6 and L7 under SALE conditions. L6 is shorter than $\mathbf{L} 7$ but also has a higher conjugate acid $\mathrm{p} K_{\mathrm{a}}$ (Table 1). From the onset of the reaction, monitoring by ${ }^{1} \mathrm{H}$ NMR performed on digested crystals indicated preferential incorporation of L6 into the crystals. L6 was eventually able to replace almost all the parent $\mathbf{L} \mathbf{1}$ pillars, whereas L7 exhibited minimal incorporation, presumably due to its steric demands and lower affinity for the metal centers.

In a second experiment, SALEM-5 crystals were exposed to an equimolar mixture of L3 and L6. These linkers have a smaller difference in basicity than L6 and L7 but differ appreciably in length (Table 1). To our surprise, the result of this reaction was quite rapid replacement of almost all $\mathbf{L} 1$ pillars with L3. Even though L6 is almost $3 \AA$ shorter than $\mathbf{L} 3$ and is expected to encounter a lower kinetic barrier as it diffuses into SALEM-5, the stronger interaction of $\mathbf{L 3}$ with $\mathrm{Zn}$ (II) (as implied by the higher $\mathrm{p} K_{\mathrm{a}}$ of $\mathrm{L}_{3} \mathrm{H}^{+}$) appears to be the critical factor in the outcome of the reaction, as the incorporation of L6 did not exceed $11 \%$.
The structural consequences of the comparatively greater affinity of the basic ligand L3 for the zinc clusters in the pillared-paddlewheel structure on SALE are remarkable. Having observed extended reaction times with the SALE of the longer (and more acidic) linkers L4 and L5, we hypothesized that the rate of these reactions could be increased if a parent with a longer pillar than SALEM-5 were used. To test the hypothesis, we examined competitive SALE of L4 and L5 on SALEM-6 and compared the progresses of these two reactions to those of the respective SALE experiments on SALEM-5. Although we expected that the longer linkers would react more rapidly with the more open compound, SALEM-6, the results of our experiment were quite surprising (Figures S15-S16, Supporting Information). L4 replaced L1 in SALEM-5 at a rate similar to that for L3 exchange into SALEM-6; L5 actually had a higher SALE rate into SALEM-5 than into SALEM-6. Although SALEM-6 offers a larger window for the longer linkers to enter, once inside the structure, it seems that they have to battle against the tight metal binding of the basic L3, which poses a greater thermodynamic challenge than the relatively acidic L1. Therefore, merely opening the cage does not necessarily guarantee more facile SALE, and the energetic factors governing SALE, such as $\mathrm{p} K_{\mathrm{a}}$, have to be taken into consideration. $^{44}$

\section{CONCLUSION}

In conclusion, we have demonstrated that the utilization of SALE for the insertion of longer pillars into a pillaredpaddlewheel system is feasible and can proceed at reasonable rates. The morphology of the crystals is not detectably altered during the reaction. Finally, linker basicity (as a surrogate for relative $\mathrm{Zn}-\mathrm{L}$ bond strength) plays an important role in the incorporation of the incoming linkers, with more basic linkers preferentially exchanging into pillared-paddlewheel structures.

\section{ASSOCIATED CONTENT}

\section{Supporting Information}

Experimental details for the synthesis of L3, L4, and L5 and the SALE procedures; ${ }^{1} \mathrm{H}$ NMR, thermogravimetric analysis, and powder X-ray diffraction data; plots of the rates of SALE in mixed linker experiments and variable linker length experiments; details pertaining to the modeling procedure. This material is available free of charge via the Internet at http:// pubs.acs.org.

\section{AUTHOR INFORMATION}

\section{Corresponding Author}

*E-mail: j-hupp@northwestern.edu; o-farha@northwestern. edu.

\section{Author Contributions}

${ }^{\perp}$ All authors have given approval to the final version of the manuscript. These authors contributed equally.

\section{Notes}

The authors declare no competing financial interest.

\section{ACKNOWLEDGMENTS}

We gratefully acknowledge the Basic Energy Sciences Office of the U.S. Dept. of Energy (Grant No. DE-FG2-08ER15967), the Foundation for Polish Science through the "Kolumb" Program (W.B.) and the Global Climate and Energy Project (E.T.) for the financial support of this project. 


\section{REFERENCES}

(1) Farha, O. K.; Eryazici, I.; Jeong, N. C.; Hauser, B. G.; Wilmer, C. E.; Sarjeant, A. A.; Snurr, R. Q.; Nguyen, S. T.; Yazaydın, A. Ö.; Hupp, J. T. J. Am. Chem. Soc. 2012, 134, 15016.

(2) Sarkisov, L. Adv. Mater. 2012, 24, 3130.

(3) Suh, M. P.; Park, H. J.; Prasad, T. K.; Lim, D.-W. Chem. Rev. 2011, 112, 782 .

(4) Farha, O. K.; Özgür Yazaydın, A.; Eryazici, I.; Malliakas, C. D.; Hauser, B. G.; Kanatzidis, M. G.; Nguyen, S. T.; Snurr, R. Q.; Hupp, J. T. Nature Chem. 2010, 2, 944.

(5) Lee, J.; Farha, O. K.; Roberts, J.; Scheidt, K. A.; Nguyen, S. T.; Hupp, J. T. Chem. Soc. Rev. 2009, 38, 1450.

(6) Kreno, L. E.; Leong, K.; Farha, O. K.; Allendorf, M.; Van Duyne, R. P.; Hupp, J. T. Chem. Rev. 2011, 112, 1105.

(7) Li, J.-R.; Sculley, J.; Zhou, H.-C. Chem. Rev. 2011, 112, 869.

(8) Khan, N. A.; Hasan, Z.; Jhung, S. H. J. Hazard. Mater. 2013, 244-245, 444.

(9) Wang, J.-L.; Wang, C.; Lin, W. ACS Catal. 2012, 2, 2630.

(10) Lee, C. Y.; Farha, O. K.; Hong, B. J.; Sarjeant, A. A.; Nguyen, S. T.; Hupp, J. T. J. Am. Chem. Soc. 2011, 133, 15858.

(11) Son, H.-J.; Jin, S.; Patwardhan, S.; Wezenberg, S. J.; Jeong, N. C.; So, M.; Wilmer, C. E.; Sarjeant, A. A.; Schatz, G. C.; Snurr, R. Q.; Farha, O. K.; Wiederrecht, G. P.; Hupp, J. T. J. Am. Chem. Soc. 2012, $135,862$.

(12) Jin, S.; Son, H.-J.; Farha, O. K.; Wiederrecht, G. P.; Hupp, J. T. J. Am. Chem. Soc. 2013, 135, 955.

(13) Kent, C. A.; Liu, D.; Ma, L.; Papanikolas, J. M.; Meyer, T. J.; Lin, W. J. Am. Chem. Soc. 2011, 133, 12940.

(14) Farha, O. K.; Shultz, A. M.; Sarjeant, A. A.; Nguyen, S. T.; Hupp, J. T. J. Am. Chem. Soc. 2011, 133, 5652.

(15) Lewis, D. W.; Ruiz-Salvador, A. R.; Gomez, A.; RodriguezAlbelo, L. M.; Coudert, F.-X.; Slater, B.; Cheetham, A. K.; MellotDraznieks, C. CrystEngComm 2009, 11, 2272.

(16) Lanchas, M.; Vallejo-Sanchez, D.; Beobide, G.; Castillo, O.; Aguayo, A. T.; Luque, A.; Roman, P. Chem. Commun. 2012, 48, 9930.

(17) Totten, R. K.; Ryan, P.; Kang, B.; Lee, S. J.; Broadbelt, L. J.; Snurr, R. Q.; Hupp, J. T.; Nguyen, S. T. Chem. Commun. 2012, 48, 4178.

(18) Yaghi, O. M.; O’Keeffe, M.; Ockwig, N. W.; Chae, H. K.; Eddaoudi, M.; Kim, J. Nature 2003, 423, 705.

(19) Cohen, S. M. Chem. Rev. 2011, 112, 970.

(20) Karagiaridi, O.; Bury, W.; Sarjeant, A. A.; Stern, C. L.; Farha, O.

K.; Hupp, J. T. Chem. Sci. 2012, 3, 3256.

(21) Karagiaridi, O.; Lalonde, M. B.; Bury, W.; Sarjeant, A. A.; Farha, O. K.; Hupp, J. T. J. Am. Chem. Soc. 2012, 134, 18790.

(22) Takaishi, S.; DeMarco, E. J.; Pellin, M. J.; Farha, O. K.; Hupp, J. T. Chem. Sci. 2013, 4, 1509.

(23) Bury, W.; Fairen-Jimenez, D.; Lalonde, M. B.; Snurr, R. Q.; Farha, O. K.; Hupp, J. T. Chem. Mater. 2013, 25, 739.

(24) Hoskins, B. F.; Robson, R. J. Am. Chem. Soc. 1990, 112, 1546.

(25) Kitaura, R.; Iwahori, F.; Matsuda, R.; Kitagawa, S.; Kubota, Y.; Takata, M.; Kobayashi, T. C. Inorg. Chem. 2004, 43, 6522.

(26) Chen, Z.; Xiang, S.; Zhao, D.; Chen, B. Cryst. Growth Des. 2009, 9, 5293.

(27) Li, J.-R.; Timmons, D. J.; Zhou, H.-C. J. Am. Chem. Soc. 2009, $131,6368$.

(28) Li, J.-R.; Zhou, H.-C. Nature Chem. 2010, 2, 893.

(29) Burnett, B. J.; Barron, P. M.; Hu, C.; Choe, W. J. Am. Chem. Soc. 2011, 133, 9984.

(30) Kim, M.; Cahill, J. F.; Su, Y.; Prather, K. A.; Cohen, S. M. Chem. Sci. 2012, 3, 126.

(31) Kim, M.; Cahill, J. F.; Fei, H.; Prather, K. A.; Cohen, S. M. J. Am. Chem. Soc. 2012, 134, 18082.

(32) Burnett, B. J.; Choe, W. CrystEngComm 2012, 14, 6129.

(33) L1 pillars are more weakly bound to the zinc cluster, as will be elaborated further in the text.

(34) Farha, O. K.; Malliakas, C. D.; Kanatzidis, M. G.; Hupp, J. T. J. Am. Chem. Soc. 2009, 132, 950.
(35) Mulfort, K. L.; Farha, O. K.; Stern, C. L.; Sarjeant, A. A.; Hupp, J. T. J. Am. Chem. Soc. 2009, 131, 3866.

(36) Shultz, A. M.; Sarjeant, A. A.; Farha, O. K.; Hupp, J. T.; Nguyen, S. T. J. Am. Chem. Soc. 2011, 133, 13252.

(37) The length of the pillars was estimated by measuring their length in relevant crystallographic information files (CIFs) featuring their structures.

(38) The $\mathrm{pK}_{\mathrm{a}}$ estimates for the monoprotonated linkers were obtained by using: $\mathrm{pK}_{\mathrm{a}}$ Calculator Plugin, Marvin 5.8.0; ChemAxon, 2012. http://www.chemaxon.com,. For the details of the method of estimation of $\mathrm{pK}_{\mathrm{a}}$ values (an approach based on calculated atomic charges), see Dixon, S. L.; Jurs, P. C. J. Comput. Chem. 1993, 14, $1460-1467$.

(39) We speculate that the success of SALE of L5 does not pertain to the rate of the diffusion of $\mathbf{L 5}$ through the MOF channel, but rather has to do with the dependence of the strength of the $\mathrm{Zn}-\mathrm{N}$ coordinate bond on the angle at which L5 approaches the zinc cluster. Having a length twice that of the parent $\mathbf{L} \mathbf{1}$ pillar, $\mathbf{L} 5$ faces a significant challenge to orient itself at a proper angle to the zinc cluster and has to rely on the presence of defects, which presumably impedes the rate of its incorporation into the framework. The presence of the bromine substituents of $\mathbf{L} \mathbf{2}$ exacerbates this problem.

(40) An inherent side effect of SALE involves development of cracks within the crystals.

(41) Nelson, A. P.; Farha, O. K.; Mulfort, K. L.; Hupp, J. T. J. Am. Chem. Soc. 2008, 131, 458.

(42) Weston, M. H.; Delaquil, A. A.; Sarjeant, A. A.; Farha, O. K.; Hupp, J. T.; Nguyen, S. T. Cryst. Growth Des. 2013, 13, 2938.

(43) Lee, C. Y.; Bae, Y.-S.; Jeong, N. C.; Farha, O. K.; Sarjeant, A. A.; Stern, C. L.; Nickias, P.; Snurr, R. Q.; Hupp, J. T.; Nguyen, S. T. J. Am. Chem. Soc. 2011, 133, 5228.

(44) In other words, the competitive linker insertion experiments that we performed indicate the favorable formation of the thermodynamic product rather than of the kinetic product.

(45) Li, T.; Kozlowski, M. T.; Doud, E. A.; Blakely, M. N.; Rosi, N. L. J. Am. Chem. Soc. 2013, 135, 11688. 